\title{
Effectiveness of amisulpride in Chinese patients with predominantly negative symptoms of schizophrenia: a subanalysis of the ESCAPE study
}

This article was published in the following Dove Press journal:

Neuropsychiatric Disease and Treatment

28 June 2017

Number of times this article has been viewed

\section{Ying Liang}

$\mathrm{Xin} \mathrm{Yu}$

Peking University Sixth Hospital, Peking University Institute of Mental Health, Key Laboratory of Mental Health, Ministry of Health (Peking University), National Clinical Research Center for Mental Disorders (Peking University Sixth Hospital), Beijing,

People's Republic of China
Correspondence: Xin Yu

Peking University Sixth Hospital, Peking

University Institute of Mental Health,

Key Laboratory of Mental Health,

Ministry of Health (Peking University), National Clinical Research Center for Mental Disorders (Peking University Sixth Hospital), 5 I Huayuanbei Road, Haidian District, Beijing 10019I, People's Republic of China

Tel +86 I0 82801999

$\mathrm{Fax}+861062026310$

Email yuxin078@।63.com
Background: Effective management strategies for the negative symptoms of schizophrenia remain an unmet need, and data on the use of antipsychotics in this population are scarce, particularly in Chinese patients. Therefore, we investigated amisulpride for the treatment of Chinese patients with predominantly negative symptoms of schizophrenia.

Methods: This post hoc subanalysis of the prospective Effectiveness and Safety of Amisulpride in Chinese Patients with Schizophrenia (ESCAPE) study included adult Chinese patients with an International Classification of Diseases-10 diagnosis of schizophrenia and predominantly negative symptoms, who received amisulpride for 8 weeks. Effectiveness outcomes included $\geq 50 \%$ decrease in Positive and Negative Syndrome Scale (PANSS) negative score, and a reduction in PANSS negative symptom score and Clinical Global Impression Severity Scale (CGI-S). The study was registered at ClinicalTrials.gov (NCT01795183).

Results: In total, 26 patients were included in the analysis. A $\geq 50 \%$ decrease in PANSS negative score from baseline to week 8 was achieved by $34.6 \%$ of patients. From baseline to week 8 , the mean PANSS negative symptom score decreased by $45.2 \%$ (31.9 to 20.7) and CGI-S decreased 1.9 points (5.2 to 3.3). The mean week 8 dose of amisulpride was lower for patients who achieved a $\geq 50 \%$ decrease in PANSS negative score at week 8 versus those who did not (481.2 vs $704.1 \mathrm{mg} /$ day). The most common treatment-related adverse events included blood prolactin increase (19.2\%) and extrapyramidal disorder (19.2\%). Weight gain was reported by one patient. Conclusion: Amisulpride effectively reduced PANSS negative symptom score and CGI-S for Chinese patients with predominantly negative symptoms of schizophrenia. No unexpected adverse events were reported.

Keywords: schizophrenia, amisulpride, negative symptoms, China

\section{Introduction}

Schizophrenia is a complex, heterogeneous mental disorder which was ranked as one of the global top 25 causes of disability in $2013 .{ }^{1}$ Schizophrenia is characterized by positive and negative symptoms; positive symptoms include delusions, hallucinations and disorganization of thought and behavior, whereas negative symptoms are categorized as a deficit or loss of function including blunted affect and social withdrawal. ${ }^{2}$ Negative symptoms can be further distinguished as primary (arising from the pathophysiology of schizophrenia), or secondary (arising from other factors including poorly controlled positive symptoms). ${ }^{3}$ Negative symptoms are proposed as one of the major causes behind the loss of vocational ${ }^{4,5}$ and social ${ }^{6}$ function associated with schizophrenia, and represent a large psychological burden on informal caregivers, ${ }^{7,8}$ and an economic burden on health systems and society. ${ }^{9}$ Several studies have found 
negative symptoms to be associated with decreased quality of life, ${ }^{10-13}$ although there is a minority of evidence to the contrary. ${ }^{14}$ In addition, the negative symptoms of schizophrenia are associated with reduced treatment compliance, which is in turn associated with poorer clinical outcomes. ${ }^{15}$

Despite the potential deleterious impact of the negative symptoms of schizophrenia on patients, caregivers and society, effective strategies for the treatment of negative symptoms remain an unmet clinical need. Although metaanalyses have shown that first- and second-generation antipsychotics have some efficacy for reducing negative symptoms, the majority of previous studies were conducted in patients in an acute episode of schizophrenia with predominantly positive, or mixed (positive and negative), symptoms. ${ }^{16-18}$ Therefore, negative symptoms were likely to have been secondary to positive symptoms, and any true reductions in negative symptoms observed in these studies are difficult to separate from those caused by amelioration of positive symptoms. Despite this, several pharmaceutical treatment strategies have been investigated specifically for the treatment of negative symptoms, including the use of antipsychotic drugs, alone and with add-on antidepressants or glutamatergic compounds; however, the effectiveness of these strategies has been inconsistent. ${ }^{19}$ Furthermore, the clinical benefit of reductions in negative symptoms observed with these existing treatment approaches is also unclear. One 2015 meta-analysis of all extant treatment approaches revealed that significant clinical benefit, measured by reduction in Clinical Global Impression Severity Scale (CGI-S), was not achieved, despite significant reductions in negative symptoms. ${ }^{20}$

Amisulpride is a second-generation antipsychotic which has been shown to be effective for the improvement of both positive and negative symptoms of schizophrenia. ${ }^{21,22}$ Unlike the majority of second-generation antipsychotics, amisulpride has been investigated in randomized controlled studies for the treatment of patients with predominantly negative symptoms of schizophrenia. ${ }^{23}$ Data from many of these placebo-controlled trials showed that amisulpride effectively reduces negative symptoms in patients with predominantly negative symptoms. ${ }^{21,24,25}$ However, typical of all antipsychotic medications, heterogeneity of response was observed. ${ }^{26}$ Based on these trials, the approved dose of amisulpride for the treatment of negative symptoms is $50-300 \mathrm{mg} /$ day.

Given the small number of previous trials conducted specifically in patients with predominantly negative symptoms of schizophrenia, there are limited data on the treatment of such patients, and this is particularly true for the Chinese population. This post hoc subanalysis of the Effectiveness and Safety of Amisulpride in Chinese Patients with Schizophrenia (ESCAPE) study was conducted to assess the effectiveness of amisulpride for treating the negative symptoms of schizophrenia in Chinese patients with predominantly negative symptoms.

\section{Methods \\ Study design}

The ESCAPE study methods have been previously published. ${ }^{27}$ In brief, the ESCAPE study was an 8-week, prospective, open-label, multicenter, single-arm Phase IV trial conducted at 13 psychiatric-specialist Tier 1 hospitals in China between 30 October 2012 and 3 December 2013. The study consisted of a screening phase followed by 8 weeks of amisulpride treatment, with clinic visits at baseline, weeks 2, 4 and 8 . The primary objective was to evaluate the effectiveness and safety of amisulpride (Solian ${ }^{\circledR}$, Sanofi, Gentilly, France) for Chinese patients with schizophrenia. The ESCAPE study was conducted in accordance with the principles of the Declaration of Helsinki, 1964 and all subsequent amendments, and received ethical approval from the following institutional ethics review boards: the Ethics Committee of Peking University Institute of Mental Health, Mental Health Center of Wuhan City Ethics Committee, Beijing Anding Hospital of Capital Medical University Ethics Committee, Beijing Huilongguan Hospital Ethics Committee, Hangzhou Seventh People's Hospital Ethics Committee, Nanjing Brain Hospital Ethics Committee, The Second Xiangya Hospital of Central South University Ethics Committee, Guangzhou City Mental Hospital Ethics Committee, Shenzhen Kangning Hospital Ethics Committee, The First Hospital of Hebei Medical University Ethics Committee, Tianjin Anding Hospital Mental Health Center of Tianjin City Ethics Committee, Shandong Mental Health Center Ethics Committee, Harbin City The First Specialist Hospital Ethics Committee, Shanghai Mental Health Center Ethics Committee, Huaxi Hospital Clinical Trials and Biomedical Ethics Committee. Written, informed consent was obtained from all study subjects. The ESCAPE study was registered at ClinicalTrials.gov (NCT01795183).

\section{Patients and treatment}

This post hoc analysis included adults (18-65 years) enrolled in the ESCAPE study who met the International Classification of Diseases (ICD)-10 criteria for schizophrenia and had predominantly negative symptoms. Patients were defined as having predominantly negative symptoms of schizophrenia if they had Positive and Negative Syndrome Scale (PANSS) 
negative symptom scale score $>20$ and PANSS negative symptom scale score $>$ PANSS positive syndrome scale score. Patients scoring $\geq 4$ (moderate) on at least 2 positive subscale items were categorized into the prominently positive group. Eligible patients could be treatment-naive or have received previous treatment with an antipsychotic and switched to amisulpride due to suboptimal treatment effect, unacceptable tolerability or other reasons. Key exclusion criteria included refractory schizophrenia or failure to respond to a full dose and full duration treatment with clozapine, contraindications to amisulpride as described in the Chinese package insert, previous or current use of amisulpride, receiving treatment with clozapine in the previous month, or long-acting antipsychotic agents in the previous 2 months, receipt of electric convulsion therapy or modified electric convulsion therapy in the previous month, and unsuitability for participation in a clinical trial due to follow-up compliance or safety issues, as assessed by the investigators.

All patients received amisulpride tablets $(50 \mathrm{mg} / \mathrm{tablet})$ administered orally for 8 weeks, in accordance with the approved Chinese labeling (accessed October 2015). For patients with predominantly negative symptoms, amisulpride was initiated at 50-300 mg/day and the dose was titrated based on a patient's individual response 1 week after initiation of treatment. Doses $>400 \mathrm{mg}$ were administered using a twice-daily dosing schedule. In order to limit withdrawal reactions in patients switching from other antipsychotic medications a cross-titration scheme was used whereby the dose of the previous medication was gradually reduced as the amisulpride dose was uptitrated, with the aim of complete discontinuation of prior medication within 1 week.

Certain concomitant medications were permitted during the study. In order to control insomnia, zolpidem ( $\leq 10 \mathrm{mg} /$ day), zopiclone $(\leq 7.5 \mathrm{mg} /$ day) or zaleplon ( $\leq 10 \mathrm{mg} /$ day) was permitted. Benzodiazepines were permitted for management of agitation ( $<1$ week continuously) and anxiety ( $<2$ weeks). Anticholinergic agents were approved for the treatment of extrapyramidal side effects. No other concomitant medications or therapies for the treatment of schizophrenia were permitted and all approved concomitant medications were given $\geq 12$ hours prior to any of the effectiveness or safety assessments.

\section{Endpoints}

The primary endpoint of the present analysis was the proportion of patients achieving a $\geq 50 \%$ decrease in PANSS negative score from baseline to week 8 . Other endpoints included the proportion of patients achieving $\mathrm{a} \geq 20 \%$ decrease in PANSS negative score from baseline to week 2, change in PANSS total score and PANSS positive and negative symptom subscales from baseline to weeks 2 , 4 and 8, changes in the individual items of the PANSS negative symptom subscale, changes in the CGI-S, and safety endpoints. Treatment-emergent adverse events (TEAE) were defined as AEs that had an onset date, or a worsening in severity from baseline (pretreatment), on or after the date of first dose up to date of last dose of amisulpride.

\section{Statistical methods}

Descriptive statistics were used to summarize demographic parameters, the use of concomitant medication, the individual items of the PANSS total score, positive and negative symptoms subscales, CGI-S and safety data. All continuous endpoints were calculated as the mean value for the entire analysis population. The proportion of patients achieving $\mathrm{a} \geq 50 \%$ decrease in PANSS negative score from baseline to week 8 , and $\mathrm{a} \geq 20 \%$ decrease in PANSS negative score from baseline to week 2 was calculated using a last observation carried forward approach to account for missing data.

Simple kappa coefficient "k" was used to assess whether agreements between variables would be expected purely by chance, with magnitude reflecting the strength of agreement; a k value, $<0.40$ was considered poor, $0.40-0.60$ moderate, 0.60-0.80 good and 0.80-1 excellent. All AEs were monitored using open AE reporting and coded using the Medical Dictionary for Regulatory Activities. The number and proportion of patients reporting TEAEs were summarized by system organ class and preferred term. Statistical analyses were performed with SAS version 9.2 (SAS Institute, Cary, NC, USA) on a Windows $\times 64$ operating system. SAS procedures PROC FREQ and PROC MEANS were employed to obtain summary statistics.

\section{Results}

\section{Patients}

A total of 26 patients with predominantly negative symptoms of schizophrenia were included in the present analysis. Of these patients, $58 \%$ were male, the majority had undifferentiated schizophrenia (62\%) and $89 \%$ had received previous treatment for schizophrenia (Table 1). The reasons for switching medication to amisulpride were not routinely recorded as a part of the original study and are, therefore, not reported. The mean starting dose of amisulpride was $253.8 \mathrm{mg} /$ day and the mean dose of amisulpride over the entire 8-week study duration was $623.9 \mathrm{mg} /$ day. The most commonly used concomitant medications were trihexyphenidyl, promethazine 
Table I Summary of baseline patient characteristics and medication use

\begin{tabular}{|c|c|}
\hline Characteristics, n (\%) & $\begin{array}{l}\text { Patients with } \\
\text { predominantly } \\
\text { negative } \\
\text { symptoms }(n=26)\end{array}$ \\
\hline Male & $15(57.7)$ \\
\hline Mean BMI, kg/m² (SD) & $23.5(4.2)$ \\
\hline \multicolumn{2}{|l|}{ Type of schizophrenia defined by ICD-I0 } \\
\hline Paranoid & $4(15.4)$ \\
\hline Hebephrenic & $0(0.0)$ \\
\hline Catatonic & $\mathrm{I}(3.8)$ \\
\hline Undifferentiated & $16(61.5)$ \\
\hline Residual & $2(7.7)$ \\
\hline Simple & $3(11.5)$ \\
\hline Received previous treatment for schizophrenia & $23(88.5)$ \\
\hline Mean starting dose of amisulpride, mg/day (SD) & $253.8(94.8)$ \\
\hline $\begin{array}{l}\text { Mean dose of amisulpride over 2-week } \\
\text { study duration, } \mathrm{mg} / \text { day (SD) }\end{array}$ & $489.2(150.6)$ \\
\hline $\begin{array}{l}\text { Mean dose of amisulpride over 4-week } \\
\text { study duration, } \mathrm{mg} / \text { day (SD) }\end{array}$ & $574.2(180.3)$ \\
\hline $\begin{array}{l}\text { Mean dose of amisulpride over 8-week } \\
\text { study duration, } \mathrm{mg} / \text { day (SD) }\end{array}$ & $623.9(190.4)$ \\
\hline \multicolumn{2}{|l|}{ Use of concomitant medication } \\
\hline Anxiety and agitation (benzodiazepines) & $3(11.5)$ \\
\hline $\begin{array}{l}\text { Extrapyramidal disorder (trihexyphenidyl, } \\
\text { promethazine and diphenhydramine) }\end{array}$ & $6(23.1)$ \\
\hline Insomnia (zolpidem, zopiclone and zaleplon) & $0(0.0)$ \\
\hline
\end{tabular}

Abbreviations: BMI, body mass index; ICD, International Classification of Diseases.

and diphenhydramine, for the management of extrapyramidal disorder (by $23.1 \%$ of patients). A patient-level data summary is provided in Table 2 .

\section{Treatment effectiveness and amisulpride dose}

The primary analysis endpoint, $\mathrm{a} \geq 50 \%$ decrease in PANSS negative score from baseline to week 8 , was achieved by $34.6 \%$ of patients (Table 3 ). In addition, a $\geq 20 \%$ decrease in PANSS negative score from baseline to week 2 was achieved by $34.6 \%$ of patients. However, it should be noted that not all of the patients who achieved a response at week 2 also achieved a response at week 8 ; six patients with a response at week 2 and three patients without a response at week 2 achieved a $\geq 50 \%$ decrease in PANSS negative score at week 8 . In addition, the kappa coefficient for agreement between response at week 2 and response at week 8 was 0.490 , indicating a moderate agreement between the two endpoints ( $P=0.012$ ). Furthermore, $\geq 20 \%$ and $\geq 50 \%$ decreases in PANSS total score from baseline to weeks 2 and 8, respectively, were both achieved by $50 \%$ of patients.

Patients who achieved $\geq 50 \%$ decrease in PANSS negative score from baseline to week 8 received a lower average dose of amisulpride during week 8 compared with those who did not achieve this endpoint; 481.2 versus $704.1 \mathrm{mg} /$ day (Table 3). In contrast, patients who did and did not achieve a $\geq 20 \%$ decrease in PANSS negative score from baseline received a comparable average dose of amisulpride during week 2.

A steady decrease in PANSS total score and negative symptom scores from baseline was observed at weeks 2, 4 and 8 and mean PANSS positive score was low at baseline and exhibited a reduction during the study (Figure 1). Mean PANSS total score and negative subscale score were significantly reduced by $50.3 \%$ and $45.2 \%$, respectively, from baseline to week 8 (Table $3 ; P<0.001$ ). The decrease in mean PANSS negative and total score from baseline to weeks 2, 4 and 8 corresponded to a decrease in mean CGI-S score over the same study time points (Figure 2). The associated reduction of mean CGI-S score from baseline to week 8 was 1.9 (36.5\%) (Table 3).

The individual seven items of the PANSS negative symptom score all decreased between baseline and week 8 (Table 3). The greatest reductions from baseline to week 8 were observed for passive/apathetic social withdrawal, blunted affect and emotional withdrawal. In addition, all items of the PANSS negative symptom score decreased from baseline to weeks 2 and 4 of amisulpride treatment (Figure 3).

\section{Safety}

Treatment-related AEs were experienced by $42.3 \%$ of the patients with predominantly negative symptoms included in this analysis (Table 4). The most common treatment-related AEs were blood prolactin increase (15.4\%) and extrapyramidal disorder (15.4\%). Weight gain was uncommon, and observed in one patient only. No patients experienced a serious AE.

\section{Discussion}

The negative symptoms of schizophrenia have a deleterious effect on the lives of patients and their caregivers, and society. ${ }^{4-9}$ Despite this, effective treatment strategies for reducing negative symptoms are currently an unmet need, and data on the use of amisulpride for treatment of patients with predominantly negative symptoms are relatively scarce, particularly in Chinese patients. This subanalysis of the ESCAPE study found that amisulpride is effective for the treatment of patients with predominantly negative symptoms of schizophrenia, and is relatively well tolerated. $\mathrm{A} \geq 50 \%$ reduction in PANSS negative score from baseline to week 8 was achieved by $34.6 \%$ of the patients included in 


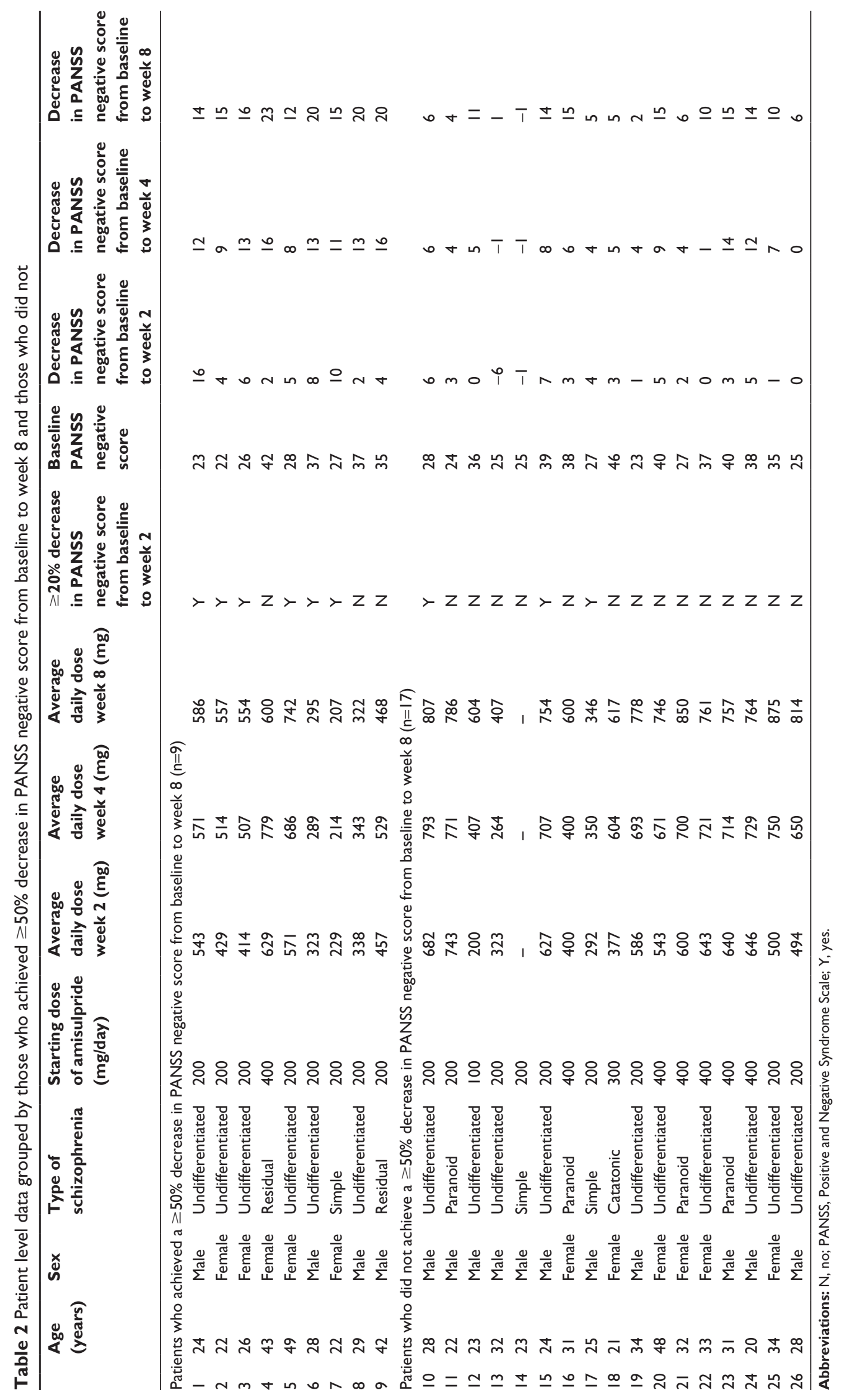


Table 3 Summary of treatment effectiveness in patients with predominantly negative symptoms of schizophrenia and corresponding average week 8 dose of amisulpride

\begin{tabular}{|c|c|}
\hline Variables $^{\mathbf{a}}$ & $\begin{array}{l}\text { Patients with } \\
\text { predominantly } \\
\text { negative } \\
\text { symptoms }(n=26)\end{array}$ \\
\hline $\begin{array}{l}\geq 50 \% \text { decrease in PANSS negative score from } \\
\text { baseline to week } 8, n(\%)^{b}\end{array}$ & $9(34.6)$ \\
\hline \multicolumn{2}{|l|}{ Mean week 8 dose of amisulpride, mg/day (SD) } \\
\hline $\begin{array}{l}\text { Patients achieving } \geq 50 \% \text { decrease in PANSS } \\
\text { negative score from baseline to week } 8\end{array}$ & $481.2(173.0)$ \\
\hline $\begin{array}{l}\text { Patients not achieving } \geq 50 \% \text { decrease in } \\
\text { PANSS negative score from baseline to } \\
\text { week } 8\end{array}$ & $704.1(151.5)$ \\
\hline $\begin{array}{l}\geq 20 \% \text { decrease in PANSS negative score from } \\
\text { baseline to week } 2, n(\%)\end{array}$ & $9(34.6)$ \\
\hline \multicolumn{2}{|l|}{ Mean week 2 dose of amisulpride, mg/day (SD) } \\
\hline $\begin{array}{l}\text { Patients achieving } \geq 20 \% \text { decrease in PANSS } \\
\text { negative score from baseline to week } 2\end{array}$ & $456.7(158.0)$ \\
\hline $\begin{array}{l}\text { Patients not achieving } \geq 20 \% \text { decrease in } \\
\text { PANSS negative score from baseline to } \\
\text { week } 2\end{array}$ & $507.4(\mid 48.3)$ \\
\hline $\begin{array}{l}\geq 50 \% \text { decrease in PANSS total score from } \\
\text { baseline to week } 8, n(\%)^{c}\end{array}$ & $13(50.0)$ \\
\hline $\begin{array}{l}\geq 20 \% \text { decrease in PANSS total score from } \\
\text { baseline to week } 2, n(\%)\end{array}$ & $13(50.0)$ \\
\hline \multicolumn{2}{|c|}{ Percent reduction in PANSS scores from baseline to week 8 , mean (SD) } \\
\hline PANSS total score & $50.3^{d}(23.3)$ \\
\hline PANSS positive score & $56.6^{\mathrm{d}}(53.3)$ \\
\hline PANSS negative score & $45.2^{\mathrm{d}}(26.4)$ \\
\hline $\begin{array}{l}\text { Change in mean CGI-S score from baseline to } \\
\text { week } 8 \text {, change (SD) (baseline - week } 8, \% \text { ) }\end{array}$ & $\begin{array}{l}-1.9(1.1) \\
(5.2 \text { to } 3.3 ; 36.5)^{d}\end{array}$ \\
\hline \multicolumn{2}{|c|}{$\begin{array}{l}\text { Change in individual PANSS negative symptom items from baseline to } \\
\text { week } 8 \text {, mean (SD) }\end{array}$} \\
\hline Blunted affect & $-1.9(1.26)$ \\
\hline Emotional withdrawal & $-1.8(1.23)$ \\
\hline Poor rapport & $-1.5(1.17)$ \\
\hline Passive/apathetic social withdrawal & $-2.0(1.15)$ \\
\hline Difficulty in abstract thinking & $-1.4(1.47)$ \\
\hline Lack of spontaneity and conversation flow & $-1.7(1.16)$ \\
\hline Stereotyped thinking & $-1.0(1.34)$ \\
\hline
\end{tabular}

Notes: aLast observation carried forward was used for patients with missing data; bIncluding six patients who achieved a $\geq 20 \%$ decrease in PANSS negative score from baseline to week 2 and three who did not; Including nine patients who achieved $a \geq 20 \%$ decrease in PANSS total score from baseline to week 2 , and four patients who did not; ${ }^{d} P<0.00$ I for Student's $t$-test.

Abbreviations: CGI-S, Global Clinical Impression Severity Scale; PANSS, Positive and Negative Syndrome Scale.

this analysis, and a reduction in the PANSS negative subscale scores over weeks 2, 4 and 8 was also observed; with a $45 \%$ reduction observed from baseline to week 8 . Furthermore, the reduction in PANSS negative score over the duration of the study appeared to correspond to a clinically meaningful reduction of 1.9 points in mean CGI-S score from baseline to week 8 .

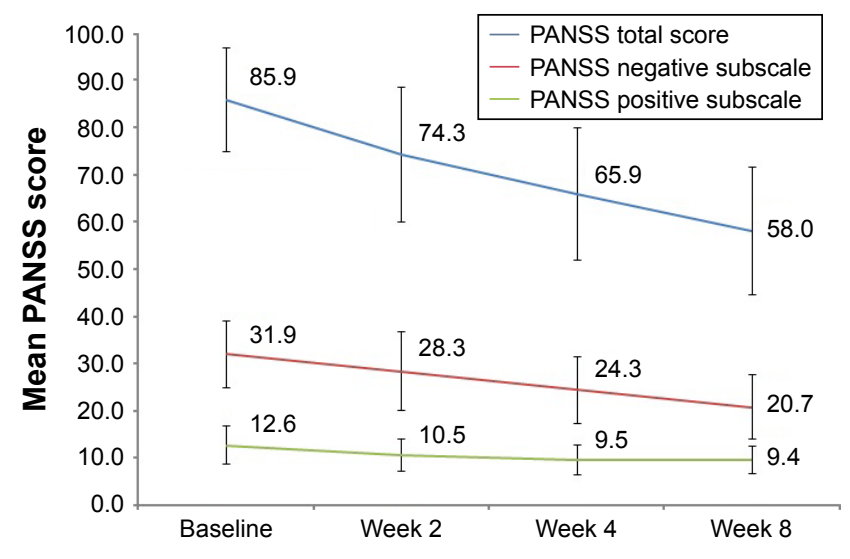

Figure I Summary of changes in PANSS total score, and positive and negative symptom scores over 8 weeks of amisulpride treatment in patients with predominantly negative symptoms of schizophrenia.

Notes: Error bars represent SD. Last observation carried forward was used for patients with missing data.

Abbreviation: PANSS, Positive and Negative Syndrome Scale.

In the present study, $50 \%$ of patients with predominantly negative symptoms of schizophrenia treated with amisulpride for 8 weeks achieved $\geq 50 \%$ reduction in PANSS total score from baseline to week 8 . This is $<66.1 \%$ of patients in the full ESCAPE study analysis, and the $65.3 \%$ of patients from a European study who received amisulpride for 6 months, who achieved this endpoint. ${ }^{27,28}$ However, these previous studies included patients with mixed and predominantly positive symptoms, which limits the comparison as it is well accepted that amisulpride is more effective at reducing positive symptoms of schizophrenia than negative symptoms. In addition, previous studies of amisulpride in patients with predominantly negative symptoms used the

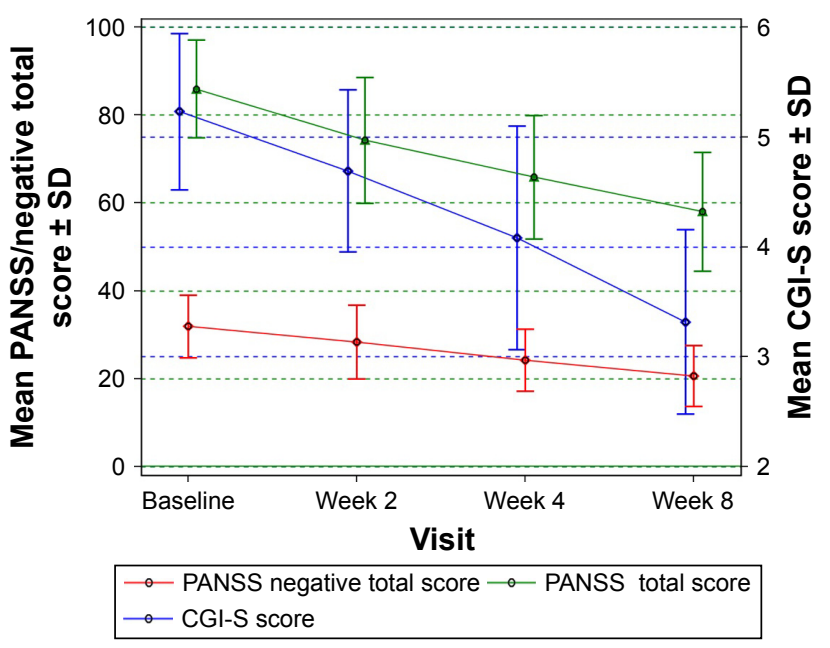

Figure 2 A comparison of the mean decrease in PANSS negative and total score and CGI-S score from baseline to weeks 2, 4 and 8 in patients with predominantly negative symptoms of schizophrenia.

Note: Last observation carried forward was used for patients with missing data. Abbreviations: CGI-S, Global Clinical Impression Severity Scale; PANSS, Positive and Negative Syndrome Scale. 

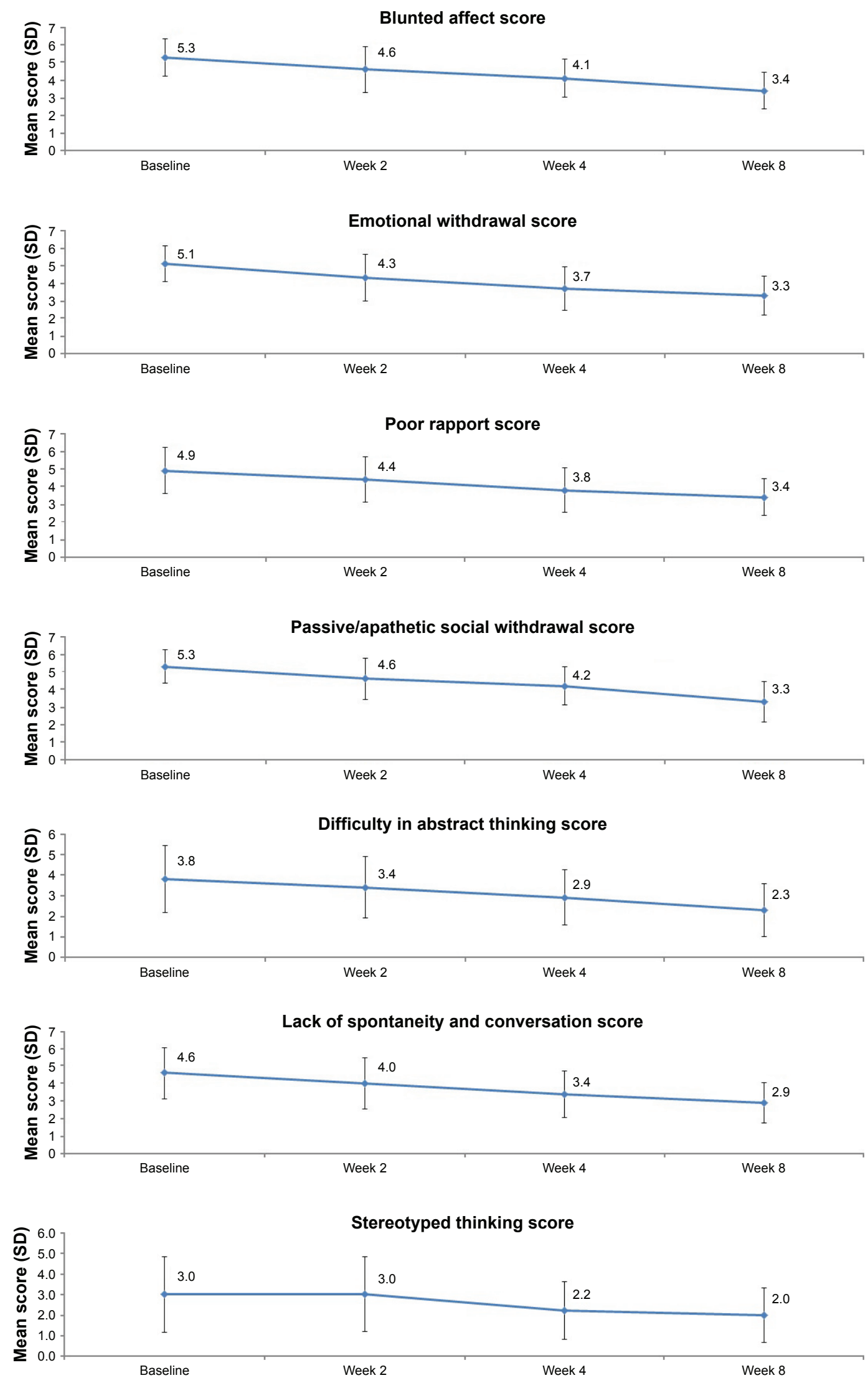

Figure 3 Change in individual items of the PANSS negative symptom score from baseline to weeks 2, 4 and 8 in patients with predominantly negative symptoms of schizophrenia.

Notes: Error bars represent SD. Last observation carried forward was used for patients with missing data.

Abbreviation: PANSS, Positive and Negative Syndrome Scale. 
Table 4 Summary of safety data

\begin{tabular}{ll}
\hline Variables, $\mathbf{n}(\%)$ & $\begin{array}{l}\text { Patients with } \\
\text { predominantly negative } \\
\text { symptoms (n=26) }\end{array}$ \\
\hline$\geq$ I treatment-related AE & II (42.3) \\
Investigations & $5(19.2)$ \\
Blood prolactin increase $(>25 \mathrm{ng} / \mathrm{mL})^{\mathrm{a}}$ & $4(15.4)$ \\
Electrocardiogram QT prolonged & $\mathrm{I}(3.8)$ \\
Weight increased & $\mathrm{I}(3.8)$ \\
Nervous system disorders & $5(19.2)$ \\
Extrapyramidal disorder & $4(15.4)$ \\
Somnolence & $\mathrm{I}(3.8)$ \\
Tremor & $\mathrm{I}(3.8)$ \\
Cardiac disorders & $2(7.7)$ \\
Gastrointestinal disorders & $\mathrm{I}(3.8)$ \\
Nausea & $\mathrm{I}(3.8)$ \\
General disorders and administration & $\mathrm{I}(3.8)$ \\
site conditions & \\
Feeling jittery & $\mathrm{I}(3.8)$ \\
Weight gain ( $>$ 7\% increase from baseline) & \\
Week 2 & $0(0.0)$ \\
Week 4 & $0(0.0)$ \\
Week 8 & $\mathrm{I}(3.8)$ \\
\hline
\end{tabular}

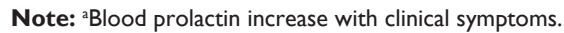
Abbreviation: $\mathrm{AE}$, adverse events.

Scales for the Assessment of Negative/Positive Symptoms (SANS), making comparison of changes in PANSS total score against these studies difficult. ${ }^{21,24,29}$ The present study also showed amisulpride is effective in patients with predominantly negative symptoms as early as week 2 of treatment, with $50 \%$ of patients achieving an early response $(\geq 20 \%$ decrease in PANSS total score from baseline to week 2). However, it should be noted that not all patients who achieved an early response at week 2 went on to achieve a $\geq 50 \%$ reduction in PANSS total score at week 8.

Randomized controlled trials conducted in patients with predominantly negative symptoms of schizophrenia have shown amisulpride to be more efficacious than placebo for the reduction of negative symptoms at doses of 50, 100 and $300 \mathrm{mg} /$ day. ${ }^{21,24,29}$ After converting between SANS total and PANSS negative scores using published conversion equations ${ }^{30}$ these previous studies reported reductions in negative symptoms equivalent to decreases in PANSS negative score from baseline of $\sim 46.2 \%, 32.7 \%, 31.9 \%$, $41.3 \%$ and $40.1 \%$ for amisulpride $300 \mathrm{mg}$ /day for 6 weeks, $100 \mathrm{mg} /$ day for 6 weeks, 12 and 24 weeks and $50 \mathrm{mg} /$ day for 12 weeks, respectively. The present study found an average reduction in PANSS negative symptom score from baseline to week 8 of $45.2 \%$, which is similar to the previous findings after amisulpride $300 \mathrm{mg} /$ day for 6 weeks, or a lower $100 \mathrm{mg} /$ day dose for 24 weeks. ${ }^{21,24}$
The average 8-week dose of amisulpride used in the present study was $623.9 \mathrm{mg} /$ day, which is higher than $50-300 \mathrm{mg} /$ day as recommended for the treatment of negative symptoms in the amisulpride labeling and as used in previous randomized controlled trials..$^{21,24,29}$ However, a previous Chinese 10-week single-arm study reported suboptimal efficacy of amisulpride 100-300 mg/day in Chinese schizophrenia patients with predominately negative symptoms, and indicated that due to inadequate control of positive symptoms under the low-dose treatment, a higher dose may be beneficial. ${ }^{31}$ In addition, an analysis of dose-related effects of amisulpride concluded that doses of amisulpride between 400 and $650 \mathrm{mg} /$ day are most appropriate for the treatment of negative and depressive symptoms in patients with an acute exacerbation of schizophrenia, and this finding is close to the dose range reported in the present analysis for patients with predominantly negative symptoms of schizophrenia. ${ }^{32}$ The relatively high average amisulpride dose used for negative patients in the ESCAPE study likely reflects the nonrandomized nature of the study, in which the dose of amisulpride was not set by treatment group and was titrated based on individual patient response to treatment. Interestingly, patients who achieved $\mathrm{a} \geq 50 \%$ reduction in PANSS negative score at week 8 in this analysis received a lower average dose of amisulpride during week 8 (481.2 $\mathrm{mg} /$ day $)$ versus those not achieving a response $(704.1 \mathrm{mg} / \mathrm{kg})$. This may suggest that for patients with negative symptoms who do not achieve an optimal respond to amisulpride there is no additional benefit of increasing the dose past a threshold of around $550 \mathrm{mg} /$ day. In addition, higher doses of amisulpride have been shown to reduce dopamine transmission, and it is, therefore, possible that at high doses a dopamine blockade induces secondary negative symptoms and causes the relationship between lower reductions in PANSS negative score and higher dose of amisulpride observed in this analysis. ${ }^{33}$ This result warrants further investigation.

The higher dose of amisulpride used in this study was associated with a modestly higher incidence of AEs versus previous studies which used 50-300 mg/day, particularly a higher incidence of extrapyramidal disorder ( $15.4 \%$ vs $4.0 \%$ ), which is also reflected in the use of anti-cholinergic drugs in $23.1 \%$ of patients. ${ }^{34}$ In contrast, the incidence of weight gain found in this analysis was similar to the previous clinical trials in patients with predominantly negative symptoms using 50-300 mg/day (3.4\% vs $4.0 \%){ }^{34}$ The incidence of hyperprolactinemia associated with amisulpride treatment observed in this study was lower than previous findings which reported rates $\sim 40 \%-85 \%$, and was also lower than the 
incidence observed in the primary analysis of the ESCAPE study $(25.9 \%){ }^{27,35}$ This result is difficult to explain and warrants future investigation, although it may be related to the characteristics of the patients selected for this subanalysis.

A previous comprehensive meta-analysis of treatments for the negative symptoms of schizophrenia showed that almost all available interventions led to a significant reduction in negative symptoms; however, the reduction in negative symptoms did not translate to a clinical benefit as assessed by CGI-S score (although the majority of studies included in the meta-analysis enrolled patients with mixed or predominantly positive symptoms). ${ }^{20}$ In contrast, the present analysis observed a decrease in mean CGI-S score of 1.9 between baseline and week 8 as well as a significant reduction in PANSS negative symptom score, which suggests a meaningful clinical benefit of amisulpride treatment in addition to a reduction of negative symptoms.

Notable heterogeneity in the response to amisulpride was observed in this study, with $34.6 \%$ of patients achieving a rapid reduction ( $\geq 20 \%$ ) in PANSS negative score at week 2 , and $34.6 \%$ of patients achieving a $\geq 50 \%$ reduction in PANSS negative score from baseline to week 8 . Such heterogeneity of treatment response to antipsychotic medications is one of the fundamental challenges in the treatment of schizophrenia. ${ }^{36}$ Interestingly, previous research suggests that patients who achieve $<20 \%$ reduction in PANSS total score from baseline to week 2 of treatment are unlikely to achieve a $\geq 50 \%$ reduction in PANSS total score between weeks 4 and $12 .{ }^{37}$ Furthermore, one previous pooled analysis also found significant heterogeneity in treatment response to amisulpride for patients with predominantly negative symptoms, and observed a correlation between severity of symptoms at baseline and response to treatment. ${ }^{38}$ Interestingly, in this analysis no difference in baseline severity of schizophrenia was observed for patients who did or did not achieve $\geq 50 \%$ reduction in PANSS total score from baseline to week 8 (data not shown).

One of the key strengths of this analysis is the reduced potential for pseudospecificity (difficulty in separating changes in primary and secondary negative symptoms) by including only patients with predominantly negative symptoms. This gives confidence that the reduction in negative symptoms observed was a true effect and not secondary due to a reduction in positive symptoms. Several limitations of this study also deserve mention; including the relatively small number of patients and that this was a post hoc subanalysis, both of which limit the strength of evidence of the results. In addition, this study was an investigation of amisulpride treatment over an acute duration of 8 weeks, which, therefore, used PANSS to assess treatment response. ${ }^{39-41}$ Longer-term assessment of social functioning endpoints over 6 months to 1 year would be of value to assess patient response and recovery and will be the subject of future research. ${ }^{39-41}$ Nonetheless, data on the treatment of Chinese patients with predominantly negative symptoms of schizophrenia are scarce, and therefore, this analysis is of value to health care professionals in China.

\section{Conclusion}

This subanalysis of the ESCAPE study suggests that 8 weeks' treatment with amisulpride is effective for the treatment of Chinese patients with predominantly negative symptoms of schizophrenia, and results in a reduction of negative symptoms as well as a clinically meaningful benefit to patients as measured by reduction in CGI-S. In addition, amisulpride was relatively well tolerated in these patients, even at higher than recommended doses. Although the present analysis included a relatively small number of patients, the findings warrant further investigation.

\section{Acknowledgments}

Sanofi (China) provided funding for this study and developed and approved the study protocol. No financial or other incentives were given to study participants. Editorial assistance for this manuscript was provided by Jake Burrell of Adelphi and paid for by Sanofi. The authors received sponsorship (AMISU_L_06155) from Sanofi (China) to conduct this study, and have no further conflicts of interest.

\section{Disclosure}

The authors report no conflicts of interest in this work.

\section{References}

1. Global Burden of Disease Study 2013 Collaborators. Global, regional, and national incidence, prevalence, and years lived with disability for 301 acute and chronic diseases and injuries in 188 countries, 1990-2013: a systematic analysis for the Global Burden of Disease Study 2013. Lancet. 2015;386(9995):743-800.

2. Kirkpatrick B, Fenton WS, Carpenter WT Jr, Marder SR. The NIMHMATRICS consensus statement on negative symptoms. Schizophr Bull. 2006;32(2):214-219.

3. Kapur S, Remington G. Atypical antipsychotics: new directions and new challenges in the treatment of schizophrenia. Annu Rev Med. 2001; 52:503-517.

4. Ventura J, Hellemann GS, Thames AD, Koellner V, Nuechterlein KH. Symptoms as mediators of the relationship between neurocognition and functional outcome in schizophrenia: a meta-analysis. Schizophr Res. 2009; 113(2-3):189-199.

5. Velligan DI, Alphs L, Lancaster S, Morlock R, Mintz J. Association between changes on the negative symptom assessment scale (NSA-16) and measures of functional outcome in schizophrenia. Psychiatry Res. 2009; 169(2):97-100. 
6. Lin $\mathrm{CH}$, Huang $\mathrm{CL}$, Chang $\mathrm{YC}$, et al. Clinical symptoms, mainly negative symptoms, mediate the influence of neurocognition and social cognition on functional outcome of schizophrenia. Schizophr Res. 2013; 146(1-3):231-237.

7. Magliano L, Fadden G, Madianos M, et al. Burden on the families of patients with schizophrenia: results of the BIOMED I study. Soc Psychiatry Psychiatr Epidemiol. 1998;33(9):405-412.

8. Magliano L, Fadden G, Economou M, et al. Family burden and coping strategies in schizophrenia: 1-year follow-up data from the BIOMED I study. Soc Psychiatry Psychiatr Epidemiol. 2000;35(3):109-115.

9. Chong HY, Teoh SL, Wu DB, Kotirum S, Chiou CF, Chaiyakunapruk N. Global economic burden of schizophrenia: a systematic review. Neuropsychiatr Dis Treat. 2016;12:357-373.

10. Fitzgerald PB, de Castella AR, Filia K, et al. A longitudinal study of patient- and observer-rated quality of life in schizophrenia. Psychiatry Res. 2003;119(1-2):55-62.

11. Fitzgerald PB, Williams CL, Corteling N, et al. Subject and observerrated quality of life in schizophrenia. Acta Psychiatr Scand. 2001; 103(5):387-392.

12. Rudnick A, Kravetz S. The relation of social support-seeking to quality of life in schizophrenia. J Nerv Ment Dis. 2001;189(4):258-262.

13. Bow-Thomas CC, Velligan DI, Miller AL, Olsen J. Predicting quality of life from symptomatology in schizophrenia at exacerbation and stabilization. Psychiatry Res. 1999;86(2):131-142.

14. Delamillieure $\mathrm{P}$, Ochoa-Torres $\mathrm{D}$, Vasse $\mathrm{T}$, et al. The subjective quality of life in deficit and nondeficit schizophrenic patients. Eur Psychiatry. 2005;20(4):346-348.

15. Hayhurst KP, Drake RJ, Massie JA, et al. Improved quality of life over one year is associated with improved adherence in patients with schizophrenia. Eur Psychiatry. 2014;29(3):191-196.

16. Leucht S, Komossa K, Rummel-Kluge C, et al. A meta-analysis of head-to-head comparisons of second-generation antipsychotics in the treatment of schizophrenia. Am J Psychiatry. 2009;166(2):152-163.

17. Leucht S, Corves C, Arbter D, Engel RR, Li C, Davis JM. Secondgeneration versus first-generation antipsychotic drugs for schizophrenia: a meta-analysis. Lancet. 2009;373(9657):31-41.

18. Leucht S, Arbter D, Engel RR, Kissling W, Davis JM. How effective are second-generation antipsychotic drugs? A meta-analysis of placebocontrolled trials. Mol Psychiatry. 2009;14(4):429-447.

19. Moller HJ, Czobor P. Pharmacological treatment of negative symptoms in schizophrenia. Eur Arch Psychiatry Clin Neurosci. 2015;265(7): 567-578.

20. Fusar-Poli P, Papanastasiou E, Stahl D, et al. Treatments of negative symptoms in schizophrenia: meta-analysis of 168 randomized placebocontrolled trials. Schizophr Bull. 2015;41(4):892-899.

21. Loo H, Poirier-Littre MF, Theron M, Rein W, Fleurot O. Amisulpride versus placebo in the medium-term treatment of the negative symptoms of schizophrenia. Br J Psychiatry. 1997;170:18-22.

22. Peuskens J, Bech P, Moller HJ, Bale R, Fleurot O, Rein W. Amisulpride vs. risperidone in the treatment of acute exacerbations of schizophrenia. Amisulpride study group. Psychiatry Res. 1999;88(2):107-117.

23. McKeage K, Plosker GL. Amisulpride: a review of its use in the management of schizophrenia. CNS Drugs. 2004;18(13):933-956.

24. Boyer P, Lecrubier Y, Puech AJ, Dewailly J, Aubin F. Treatment of negative symptoms in schizophrenia with amisulpride. Br J Psychiatry. 1995;166(1):68-72.
25. Paillere-Martinot ML, Lecrubier Y, Martinot JL, Aubin F. Improvement of some schizophrenic deficit symptoms with low doses of amisulpride. Am J Psychiatry. 1995;152(1):130-134.

26. Levine SZ, Leucht S. Treatment response heterogeneity in the predominant negative symptoms of schizophrenia: analysis of amisulpride vs placebo in three clinical trials. Schizophr Res. 2014;156(1):107-114.

27. Liang Y, Cao C, Zhu C, et al. The effectiveness and safety of amisulpride in Chinese patients with schizophrenia: an 8-week, prospective, openlabel, multicenter, single-arm study. Asia Pac Psychiatry. 2016;8(3): 241-244.

28. Sechter D, Peuskens J, Fleurot O, Rein W, Lecrubier Y. Amisulpride vs. risperidone in chronic schizophrenia: results of a 6-month double-blind study. Neuropsychopharmacology. 2002;27(6):1071-1081.

29. Danion JM, Rein W, Fleurot O. Improvement of schizophrenic patients with primary negative symptoms treated with amisulpride. Amisulpride Study Group. Am J Psychiatry. 1999;156(4):610-616.

30. van Erp TG, Preda A, Nguyen D, et al. Converting positive and negative symptom scores between PANSS and SAPS/SANS. Schizophr Res. 2014;152(1):289-294.

31. Kuang Y, Li X, Zhong X, Li X. A preliminary clinical study of amisulpride in treatment of forty patients with schizophrenia. J Psychiatry. 2009;22(3):180-181.

32. Muller MJ, Wetzel H, Eich FX, Rein W, Puech A, Benkert O. Doserelated effects of amisulpride on five dimensions of psychopathology in patients with acute exacerbation of schizophrenia. $J$ Clin Psychopharmacol. 2002;22(6):554-560.

33. McKeage K, Plosker GL. Amisulpride: a review of its use in the management of schizophrenia. CNS Drugs. 2004;18(13):933-956.

34. Coulouvrat C, Dondey-Nouvel L. Safety of amisulpride (Solian): a review of 11 clinical studies. Int Clin Psychopharmacol. 1999;14(4): 209-218.

35. Peuskens J, Pani L, Detraux J, De Hert M. The effects of novel and newly approved antipsychotics on serum prolactin levels: a comprehensive review. CNS Drugs. 2014;28(5):421-453.

36. Leucht S, Cipriani A, Spineli L, et al. Comparative efficacy and tolerability of 15 antipsychotic drugs in schizophrenia: a multiple-treatments meta-analysis. Lancet (London, England). 2013;382(9896):951-962.

37. Samara MT, Leucht C, Leeflang MM, et al. Early improvement as a predictor of later response to antipsychotics in schizophrenia: a diagnostic test review. Am J Psychiatry. 2015;172(7):617-629.

38. Levine SZ, Leucht S. Treatment response heterogeneity in the predominant negative symptoms of schizophrenia: analysis of amisulpride vs placebo in three clinical trials. Schizophr Res. 2014;156(1):107-114.

39. Royal Australian and New Zealand College of Psychiatrists clinical practice guidelines for the treatment of schizophrenia and related disorders. Aust N Z J Psychiatry. 2005;39(1-2):1-30.

40. Kreyenbuhl J, Buchanan RW, Dickerson FB, Dixon LB. The schizophrenia patient outcomes research team (PORT): updated treatment recommendations 2009. Schizophr Bull. 2010;36(1):94-103.

41. Lehman AF, Lieberman JA, Dixon LB, et al. Practice guideline for the treatment of patients with schizophrenia, second edition. Am JPsychiatry. 2004;161(Suppl 2):1-56.
Neuropsychiatric Disease and Treatment

\section{Publish your work in this journal}

Neuropsychiatric Disease and Treatment is an international, peerreviewed journal of clinical therapeutics and pharmacology focusing on concise rapid reporting of clinical or pre-clinical studies on a range of neuropsychiatric and neurological disorders. This journal is indexed on PubMed Central, the 'PsycINFO' database and CAS,

\section{Dovepress}

and is the official journal of The International Neuropsychiatric Association (INA). The manuscript management system is completely online and includes a very quick and fair peer-review system, which is all easy to use. Visit http://www.dovepress.com/testimonials.php to read real quotes from published authors. 